\title{
Advancing interprofessional education through the use of \\ high fidelity human patient simulators
}

Pamela L. SMITHBURGER, Sandra L. KANE-GILL, Megan A. KLOET, Brian LOHR, Amy L. SEYBERT. Received (first version): $\quad$ 15-Feb-2013

Accepted: 21-Apr-2013

\begin{abstract}
${ }^{*}$
Background: Modern medical care increasingly requires coordinated teamwork and communication between healthcare professionals of different disciplines. Unfortunately, healthcare professional students are rarely afforded the opportunity to learn effective methods of interprofessional (IP) communication and teamwork strategies during their education. The question of how to best incorporate IP interactions in the curricula of the schools of health professions remains unanswered. Objective: We aim to solve the lack of IP education in the pharmacy curricula through the use of high fidelity simulation (HFS) to allow teams of medical, pharmacy, nursing, physician assistant, and social work students to work together in a controlled environment to solve cases of complex medical and social issues.
\end{abstract}

Methods: Once weekly for a 4-week time period, students worked together to complete complex simulation scenarios in small IP teams consisting of pharmacy, medical, nursing, social work, and physician assistant students. Student perception of the use of HFS was evaluated by a survey given at the conclusion of the HFS sessions. Team communication was evaluated through the use of Communication and Teamwork Skills (CATS) Assessment by 2 independent evaluators external to the project.

Results: The CATS scores improved from the HFS sessions 1 to $2(p=0.01), 2$ to $3(p=0.035)$, and overall from 1 to $4(p=0.001)$. The inter-rater reliability between evaluators was high $(0.85,95 \%$ $\mathrm{Cl} 0.71,0.99)$. Students perceived the HFS improved: their ability to communicate with other professionals (median $=4$ ); confidence in patient care in an IP team (median=4). It also stimulated

\footnotetext{
*Pamela L. SMITHBURGER. PharmD, BCPS. Assistant Professor. Department of Pharmacy and Therapeutics, School of Pharmacy, University of Pittsburgh. Pittsburgh PA (United States).

Sandra L. KANE-GILL. PharmD, MSc. Associative Professor. Department of Pharmacy and Therapeutics, School of Pharmacy, University of Pittsburgh. Pittsburgh PA (United States).

Megan A. KLOET. PharmD, BCPS. Critical Care

Resident. UPMC, Department of pharmacy. Pittsburgh PA (United States).

Brian LOHR. PharmD. Clinical Pharmacist. UPMC Department of Pharmacy. Pittsburgh PA (United States) Amy L. SEYBERT. PharmD. Associative Professor and Department Chair. Department of Pharmacy and Therapeutics, School of Pharmacy, University of Pittsburgh. Pittsburgh PA (United States).
}

student interest in IP work (median=4.5), and was an efficient use of student time (median=4.5) Conclusion: The use of HFS improved student teamwork and communication and was an accepted teaching modality. This method of exposing students of the health sciences to IP care should be incorporated throughout the curricula.

Keywords: Patient Simulation; Interprofessional Relations; Patient Care Team; Education, Professional; United States

\section{AVANZANDO LA EDUCACIÓN INTERPROFESIONAL MEDIANTE EL USO \\ DE SIMULADORES DE PACIENTES HUMANOS DE ALTA FIDELIDAD}

\section{RESUMEN}

Antecedentes: Los cuidados médicos modernos requieren cada día más trabajo en equipo coordinado y comunicación entre profesionales de la salud de diferentes disciplinas.

Desafortunadamente, los estudiantes de profesiones de la salud rara vez pueden permitirse la oportunidad de aprender métodos efectivos de comunicación interprofesional (IP) y estrategias e trabajo en grupo durante su educación. La pregunta de cuál es la mejor forma de incorporar las interacciones IP en los curricula de las facultades de profesionales de la salud permanece sin respuesta.

Objetivo: Intentamos resolver al falta de educación IP en el curriculum de farmacia mediante el uso de simulación de alta fidelidad (HFS) para permitir que equipos de médicos, farmacéuticos, enfermeras, auxiliares médicos, y trabajadores sociales trabajasen juntos en un ambiente controlado para resolver casos de problemas médicos y sociales complejos.

Métodos: Una vez a la semana, durante un periodo de 4 semanas, los estudiantes trabajaron juntos para completar escenarios de simulación complejos en pequeños grupos IP consistentes en estudiantes de farmacia, medicina, enfermería, trabajo social, y auxiliar médico. Se evaluó la percepción de los estudiantes sobre el uso de la HFS mediante un cuestionario al final de las sesiones de HFS. La comunicación en equipo fue evaluada mediante el Communication and Teamwork Skills (CATS) independientemente por dos evaluadores externos al proyecto.

Resultados: Las puntuaciones del CATS mejoraron de la sesión de HFS 1 a la $2(p=0,01)$, de la 2 a la 3 $(p=0,035)$, $y$ en general de la 1 a la $4(p=0,001)$. La 
fiabilidad inter-evaluadores fue alta $(0,85 ; 95 \% \mathrm{CI}$ 0,71 - 0,99). Los estudiantes percibieron que la HFS mejoraba: su capacidad de comunicar con otros profesionales (mediana=4); la confianza en la atención al paciente en un equipo IP (mediana=4). También estimuló el iteres de los estudiantes en el trabajo IP (mediana 4,5), y fue una utilización eficiente del tiempo del estudiante (mediana 4,5). Conclusión: El uso de HFS mejoró el trabajo en equipo y la comunicación de los estudiantes y fue una modalidad de enseñanza aceptada. Este método de exponer a los estudiantes de ciencias de la salud a la atención IP debería incorporarse en los curricula.

Palabras clave: Simulación de Paciente; Relaciones Interprofesionales; Equipo de Atención al Paciente; Educación Profesional; Estados Unidos

\section{INTRODUCTION}

Modern medical care increasingly requires coordinated teamwork and communication between healthcare professionals of different disciplines. It has been demonstrated that a team of two or more people make less mistakes than persons acting independently, especially in healthcare. ${ }^{1-5}$ Interprofessional (IP) education is defined as an experience when 2 or more professions learn from, with, and about each other to improve teamwork and patient care. ${ }^{6,7}$ Interprofessional education, or sometimes called team-based training, is regarded by the World Health Organization, the Institute of Medicine, and the Prevention Education Resource Center as a potential way to reduce medical errors and improve the healthcare delivery system. ${ }^{8-10}$ Unfortunately, students training to be healthcare professionals are rarely afforded the opportunity to learn effective methods of communication and teamwork strategies between the different professions during their education. ${ }^{5}$ Upon completion of their degree, the lack of IP exposure as a student may lead to poor communication and inefficient IP team healthcare functioning and collaboration in the workforce. It has been demonstrated that collaborative, IP learning and training is a central component in the provision of safe and quality patient care. ${ }^{6,7}$ While the Institute of Medicine, Association of American Medical Colleges, and the Accreditation Council for Pharmacy Education (ACPE) have recognized the importance of IP education, the question of how to best incorporate IP experiences in the curricula of the schools of health professions remains unknown. ${ }^{11-15}$

One possible educational tool is the use of simulation based learning. This learning method is used in medical, nursing, and pharmacy education, but has not traditionally been incorporated into IP education experiences for students. ${ }^{16-19}$ The use of simulation for healthcare education has been defined as an activity or event that replicates practice. $^{20}$ Simulation based learning provides students with an opportunity to apply learned concepts and skills in a realistic clinical setting that is a safe and controlled educational environment. ${ }^{11}$ In 2006, ACPE released standards and guidelines for pharmacy education programs leading to the doctorate of pharmacy degree. In this document, ACPE recommends that faculty use educational technologies and techniques incorporating a variety of methods of educational delivery and assessment. These standards support the use of simulation to aid in the development of critical thinking and problem-solving skills. ${ }^{12,20}$

Simulation experiences can be provided in variety of ways (virtual computer programs, standardized patients), however, simulation with mannequins is considered high fidelity simulation (HFS) because mannequins are the most sophisticated and closest means to mimicking real-life patients. These devices are life-sized human simulator mannequins that possess many human anatomical features. They are interfaced with a computer program that can produce human physiologic functions in response to the student's actions and medical treatment plan. These include changes in respiratory rate, heart rate, blood pressure, bowel, heart and lung sounds, as well as sweating, bleeding, and responding to medication therapy. Students interact with the mannequin on many levels, such as performing a physical exam and drug administration. Simulated scenarios are created by instructors to incorporate learning objectives into patient cases that are realistic to situations that the students will encounter in clinical practice. The simulated scenarios may contain complex medical conditions as well as language barriers, patient-family social issues, lack of readily available clinical information, and other communication conflicts that could arise in a real life situation. Interprofessional team work is necessary to adequately care for the patient's complex medical and social problems. This necessitates the team to identify patient care issues and discuss them with members of the interdisciplinary team. Through discussion and practice in a safe and controlled environment, the learners will discover how their professional role contributes to patient care and develop the skills necessary to effectively work with healthcare providers from other disciplines through improved communication and a better understanding of roles and responsibilities of others. $^{16-18}$

The goal of this project was to determine if HFS is an effective and accepted approach to improving IP communication and teamwork for pharmacy students with other students in the health sciences

\section{METHODS}

This feasibility project received IRB approval through the University of Pittsburgh IRB, and it was conducted at the University of Pittsburgh where the schools of medicine, pharmacy, nursing, social work and physician assistant studies are located in close proximity to each other. Students were included in this investigation if they volunteered to participate in an elective IP experience. Four simulation scenarios, which were three hour sessions, occurred weekly over a four week time period 
during an elective IP student experience that was available to students that were in the last year of their professional education. Students worked together in a small team consisting of pharmacy, medical, nursing, social work, and physician assistant students. The complex clinical scenario required the students to engage in teamwork to effectively manage the patient case. The complex clinical scenarios were developed and reviewed by an IP team of University of Pittsburgh faculty members, which included representatives from all of the disciplines involved. This IP faculty team ensured that the simulation scenarios incorporated aspects and problems that are important across the spectrum of professions.

The simulation scenarios centered around an individual with a hypertensive crisis and bacteremia whose clinical course progressed through several transitions of care. The patient case transitioned through the four simulation scenarios from an outpatient dialysis center, to the emergency department, then an intensive care unit, and finally to a general medicine floor. The students assumed the role of their respective profession in each of the clinical environments. The objectives of each simulation consisted of the development of a problem list and treatment plan, as well as effectively communicate to other healthcare practitioners the necessary information to facilitate an effective transfer of care for the patient. Students conducted patient interviews to obtain pertinent medical and social information. The students also interacted with a faculty member who was playing the role of the patient's daughter. The students were also able to watch the hemodynamic and physiologic changes that occur to the simulated patient based upon their treatment plan through responses such as changes in blood pressure, temperature control, and resolution of seizures. The faculty facilitator then debriefed the students on the success of their treatment plan and the collaboration between the different team members immediately after the completion of the scenario. The debriefing session provided immediate feedback that allowed the students to reflect on their performance and apply new skills during the next simulation scenario.

To provide an evaluation of communication and team skills, the Communication and Teamwork Skills (CATS) Assessment was employed. This is a published, objective tool that is designed to evaluate communication and teamwork. ${ }^{19}$ This tool assesses the coordination of care, situational awareness, and IP communication. ${ }^{19}$ The simulation case were videotaped and evaluated by 2 faculty members who were independent of the course, using the CATS assessment tool. Two faculty members were utilized to confirm the inter-rater reliability of the CATS assessment tool. Student acceptance and impression of the use of HFS in an IP environment was assessed through the use of an anonymous, 8 question Likert based survey (1=strongly disagree; $5=$ strongly agree) after the 4 HFS sessions, evaluating perceived benefit of HFS for IP education. (Table 1 )

Descriptive Statistics were used to evaluate the survey of perceived benefit of HFS for IP education. To evaluate the improvement in CATS scores from the simulation session, ANOVA with Bonferonni for comparison between groups was utilized. A result was considered statistically significant if $p<0.05$. The agreement of the independent raters was assessed by an intra-class correlation coefficient (ICC).

\section{RESULTS}

Overall, 2 pharmacy, nursing, and physician assistant students, as well as a medical and master of social work student, who were all in the last year of their education, were included in this feasibility project. Upon completion and evaluation of the videotaped simulation scenarios, the CATS scores significantly improved from the HFS session 1 to 2 $(p=0.01)$, session 2 to $3(p=0.035)$, and overall from session 1 to $4(p=0.001)$. The CATS scores did not significantly improve from sessions 3 to $4(p=0.07)$. The inter-rater reliability, based on the ICC, between the independent evaluators who utilized the CATS assessment was high $(0.85,95 \% \mathrm{Cl} 0.71$, $0.99)$, thus, indicating high agreement.

The results of the student perception survey are displayed in table 1 . Upon evaluation of student perception of the HFS, the students agreed or strongly agreed that the HFS sessions improved their ability to communicate with other professionals, improved confidence in patient care in an IP team, stimulated student interest in IP work, and was an efficient use of student time.

\section{DISCUSSION}

The use of HFS in an IP environment not only improved IP communication and teamwork, as evidenced by the increasing CATS score, but it was also widely accepted by students. Interprofessional communication is an important aspect of modern medical care. However, healthcare students are

\begin{tabular}{|l|c|}
\hline \multicolumn{1}{|l|}{ Table 1. Results of the student perception survey (1-5)a. N=8 } & Median (Range) \\
\hline Measure & $4(3-5)$ \\
\hline The use of high fidelity simulation: & $4(3-5)$ \\
\hline Improved my ability to communicate with other professionals & $4.5(4-5)$ \\
\hline Improved my confidence in caring for a patient in an IP team. & $4.5(4-5)$ \\
\hline \multicolumn{1}{|c|}{ Stimulated my interest in inter-professional work } & $4(3-5)$ \\
\hline \multicolumn{2}{|c|}{$1(1)$} \\
\hline I would like to participate in more sessions that incorporate simulation & $4(4)$ \\
\hline There were too many simulation sessions during the IP experience. & $4(4)$ \\
\hline There should be more simulation sessions during the IP experience. & \\
\hline The simulation sessions met my expectations. & \\
\hline${ }^{a}: 1=$ strongly disagree; 5= strongly agree & \\
\hline
\end{tabular}


rarely afforded the opportunity to work in an IP environment during their educational careers. It is postulated that this is due to classroom size restraints, difficulties in scheduling, and faculty workload. Simulation based learning creates a unique opportunity that divides a larger classroom setting into smaller, more intimate groups of students. The simulation scenarios, although initially time intensive, can be utilized and modified for subsequent simulation sessions

Health care professionals are primarily educated in silos, interacting with only their profession for the majority of their educational careers.. The use of simulation centers, that house many high fidelity simulators, would enable several different professions to be separated into small IP teams and rotated through different scenarios. Overall, there is a lack of opportunities to bring different disciplines together during their formal education. ${ }^{21-24}$ Interprofessional team simulations are commonly encountered in rapid response and trauma training, as well as in the ICU and operating room environments. ${ }^{25-27}$ By using simulated scenarios in these settings, a safe environment is created that allows participants the opportunity to concentrate on specific skill sets and communication between different team members. ${ }^{17}$ Through the use of HFS, objective improvement in team performance, including improved communication and cohesiveness, as well as refined technical skills resulted. ${ }^{25-27}$ The use of simulations to expand the opportunity for pharmacy students to interact with other professional students earlier in their education would help foster the development of enhanced communication skills, as well as a better understanding of the importance of team based patient care. The use of high fidelity patient simulators to provide an IP learning opportunity for medical, pharmacy, nursing, physician assistant, and social work students has not been done, therefore this project may lay the foundation for future training throughout the schools of the health sciences and be applied on a larger scale as a model for other institutions.

There are several limitations to this investigation. One limitation was the presence of possible confounding factors that could impact the CATS assessment scores. The improvement in the CATS scores may have been influenced by factors that were unable to be controlled by the investigators, such as students becoming more comfortable with each other as a result of working together in previous simulated scenarios. Another limitation is the small number of students involved with the investigation. However, as one of the main goals of the investigation was to assess the feasibility of using HFS in an IP environment. Based upon the success of this investigation, the authors believe that this IP teaching method can be employed larger scale IP studies. The generalizability of the results of this study may be limited due to the simulation experience at the University of Pittsburgh, availability of high fidelity simulators, and the close proximity of the different schools of the health science.

\section{CONCLUSIONS}

This feasibility project was a multidisciplinary project that involved faculty members and students from several schools of the Health Sciences, including Medicine, Pharmacy, Nursing, Social Work, and Physician Assistant Studies. While this innovation in education initially involved a small cohort of IP students, the successful implementation and the demonstrated benefit in teamwork and communication between the cohort of IP students, provides evidence that this instructional design can be applied to the Schools of the Health Sciences as a whole. Future investigations are needed to further evaluate the effectiveness of HFS in an IP educational environment, specifically focusing on qualitative results, such as student attitudes, behaviors, and feelings associated with the use of HFS. Overall, the use of HFS may create opportunities for hundreds of health science students to interact through simulation based learning to improve teamwork and communication.

\section{CONFLICT OF INTEREST}

The authors have no conflicts of interest to disclose.

This project do not receive funding or sponsorship.

\section{References}

1. Salas E, Cannon-Bowers JA, Johnston JH. How can you turn a team of experts into an expert team? Emerging training strategies. In: Naturalistic Decision Making. Mahwah, NJ: Lawrence Erlbaum Assoc 1997:359-70.

2. Baker DP, Day R, Salas E. Teamwork as an essential component of high-reliability organizations. Health Serv Res. 2006;41(4 Pt 2):1576-1598.

3. Smith-Jentsch KA, Salas E, Baker DP. Training team performance-related assertiveness. Pers Psychol. 1996;49(4):909-936.

4. Salas E, Cannon-Bowlers JA. The anatomy of team training . In: Training and retraining: A Handbook for Business, Industry, Government, and the Military. New York, NY:Macmillan Reference; 2000:312-335.

5. Janson SL, Cooke M, McGrath KW, Kroon LA, Robinson S, Baron RB. Improving chronic care of type 2 diabetes using teams of interprofessional learners. Acad Med. 2009;84(11):1540-1548. doi: 10.1097/ACM.0b013e3181bb2845.

6. Center for Advancement of Interprofessional Education (CAIPE). http://www.caipe.org.uk/about-us/defining-ipe/ (Accessed August 30, 2011).

7. The Institute of Medicine: Bridge to Quality Report endorses the movement toward an interprofessional approach to patient care [Institute of Medicine, Crossing the Quality Chasm: A New Health System for the 21st Century, National Academy Press, Washington, DC; 2001 
8. Institute of Medicine. Health Professions Education: A Bridge to Quality. Washington, DC: National Academy Press; 2003.

9. World Health Organization. Working Together for Health: The World Health Report 2006. Geneva, Switzerland: World Health Organization; 2006.

10. Prevention Education Resource Center. Interprofessional education. Available at: http:// www.teachprevention.org/interprofessional.php (Accessed February 3, 2010).

11. Steadman RH, Coates WC, Huang YM, Matevosian R, Larmon BR, McCullough L, Ariel D. Simulation-based training is superior to problem-based learning for the acquisition of critical assessment and management skills. Crit Care Med. 2006;34(1):151-157.

12. ACPE. accreditation standards and guidelines for the professional program in Pharmacy Leading to the Doctor of Pharmacy Degree, Standard 25.7. Chicago, ILL: 2006. Available at: http://www.acpeaccredit.org/pdf/ACPE_Revised_PharmD_Standards_Adopted_Jan152006.pdf (Accessed on May 2, 2011).

13. Association of American Medical Colleges. Interprofessional Education: Current Rationale, Resources, and Relevance. Available at https://www.aamc.org/download/183128/data/inter-professional_education_current_rationale_resources.pdf (Accessed Aug 30, 2011)

14. Long KA. Institute of Medicine report: health professions education: A bridge to quality report. Policy Polit Nurs Pract 2003;4(4):259-262.

15. ACPE. accreditation standards and guidelines for the professional program in Pharmacy Leading to the Doctor of Pharmacy Degree, Standard 25.7. Chicago, ILL: 2011. Available at: http://www.acpeaccredit.org/pdf/S2007Guidelines2.0_ChangesIdentifiedInRed.pdf (Accessed on June 7, 2011).

16. Miller KK, Riley W, Davis S, Hansen HE.In situ simulation: A method of experiential learning to promote safety and team behavior. J Perinat Neonatal Nurs. 2008;22(2):105-113. doi: 10.1097/01.JPN.0000319096.97790.f7.

17. Forsythe L. Action research, simulation, team communication, and bringing the tacit into voice society for simulation in healthcare. Simul Healthc. 2009;4(3):143-148. doi: 10.1097/SIH.0b013e3181986814.

18. Helmreich RL, Merritt AC, Wilhelm JA. The evolution of crew resource management training in commercial aviation. Int J Aviat Psychol. 1999;9(1):19-32.

19. Frankel A, Gardner R, Maynard L, Kelly A. Using the communication and teamwork skills (CATS) assessment to measure health care team performance. Jt Comm J Qual Patient Saf. 2007;33(9):549-558.

20. ACPE. accreditation standards and guidelines for the professional program in Pharmacy Leading to the Doctor of Pharmacy Degree, Standard 11.2. Chicago, ILL: 2006. Available at: http://www.acpeaccredit.org/pdf/ACPE_Revised_PharmD_Standards_Adopted_Jan152006.pdf (Accessed on May 2, 2011).

21. Salas E, Cannon-Bowers JA, Johnston JH. How can you turn a team of experts into an expert team? emerging training strategies. In: Naturalistic Decision Making. Mahwah, NJ: Lawrence Erlbaum Assoc 1997:359-370.

22. Baker DP, Day R, Salas E. Teamwork as an essential component of high-reliability organizations. Health Serv Res. 2006;41(4 Pt 2):1576-1598.

23. Smith-Jentsch KA, Salas E, Baker DP. Training team performance-related assertiveness. Pers Psychol. 1996;49(4):909-936.

24. Salas E, Cannon-Bowlers JA. The anatomy of team training. In: Training and Retraining: A Handbook for Business, Industry, Government, and the Military. New York, NY:Macmillan Reference; 2000:312-335.

25. Falcone RA Jr, Daugherty M, Schweer L, Patterson M, Brown RL, Garcia VF.Multidisciplinary pediatric trauma team training using high fidelity trauma simulation. J Pediatr Surg. 2008;43(6):1065-1071. doi: 10.1016/j.jpedsurg.2008.02.033.

26. Freeth D, Ayida G, Berridge EJ, Mackintosh N, Norris B, Sadler C, Strachan A. Multidisciplinary obstetric simulated emergency scenarios (MOSES) promoting patient safety in obstetrics with teamwork-focused interprofessional simulations. J Contin Educ Health Prof. 2009;29(2):98-104. doi: 10.1002/chp.20018.

27. Paige JT, Kozmenko V, Yang T, Paragi Gururaja R, Hilton CW, Cohn I Jr, Chauvin SW. High-fidelity, simulation-based, interdisciplinary operating room team training at the point of care. Surgery. 2009;145(2):138-146. doi: 10.1016/j.surg.2008.09.010. 